\title{
Estudo Comparativo do Crescimento de Plantas de Tomate e Milho sob Condições de Salinidade
}

\author{
Egídio Bezerra Neto ${ }^{1}$ and Rejane Jurema Mansur Custódio Nogueira ${ }^{2 *}$ \\ UFRPE - ${ }^{1}$ Depto. de Química; ${ }^{2}$ Depto. de Biologia - 52171-030, Recife, PE - Brasil.
}

\begin{abstract}
Plants of tomato and maize were grown in hydroponic solution with and without the addition of sodium chloride in order to evaluate some growth parameters of one $C_{3}$ and one $C_{4}$ species. After 30 days under the saline stress treatment there was no significant difference between both species regarding to leaf biomass allocation. The stem biomass allocation decreased for both the tomato and the maize plants. This was due to salt treatment, while root biomass allocation increased. The Absolute growth rate was the most affected parameter by the NaCl treatment for which values were obtained for both species. The leaf area also decreased due to the sodium chloride treatment. The leaf area rate increased for the stressed tomato plants, while it tend to decrease for maize plants under saline treatment.
\end{abstract}

Key words: Zea mays, Lycopersicum esculentum, leaf area, dry matter, fresh matter.

\section{INTRODUÇÃO}

Elevadas concentrações de sais no solo provocam uma redução no potencial osmótico, interfere negativamente no processo de absorção de água pelas plantas, e como consequência causa uma redução no seu crescimento (Rebouças et al., 1989). Tais efeitos variam com a espécie vegetal e com da natureza dos sais. Além do mais, pode ocorrer tembém efeito tóxico dos íons em excesso na solução do solo (Epstein, 1975). Tal toxicidade pode provocar desequilíbrio nutricional e prejudicar $o$ metabolismo das plantas submetidas ao estresse salino (Marschner, 1990).

Dentre as injúrias provocadas pela salinidade sobre o metabolismo das plantas, merece destaque: o efeito sobre os fitohormônios e fotossíntese. As citocininas, fitohormônios que atuam no retardamento da senescência das folhas, são sintetizadas nas raízes e translocadas para a parte aérea das plantas. Quando estas são cultivadas em condições de salinidade, o transporte das citocininas é prejudicado causando como consequência um envelhecimento prematuro das folhas (Fletcher, 1969).
A literatura tem comprovado que plantas $\mathrm{C}_{4}$ são mais eficientes que as $\mathrm{C}_{3}$, no que diz respeito à eficiência do uso da água. No entanto, especificamente em relação à influência do estresse salino sobre o crescimento comparativo, este tema carece de estudos para que o comportamento das plantas frente à essas condições adversas possa ser generalizado.

O presente trabalho tem por objetivo comparar os efeitos da salinidade sobre alguns parâmetros do crescimento de uma espécie $\mathrm{C}_{3}$ e uma $\mathrm{C}_{4}$, respectivamente, o tomate (Lycopersicum esculentum Mill) e o milho (Zea mays L.).

\section{MATERIAL E MÉTODOS}

O experimento foi conduzido na casa de vegetação do Departamento de Química da UFRPE, em Recife-PE, nos meses de julho e agosto de 1995. O delineamento constou de um arranjo fatorial completo entre duas espécies vegetais e dois níveis de salinidade, utilizandose blocos ao acaso, com quatro repetições. As espécies estudadas foram o tomate, variedade IPA 6, e o milho, hibrido G 85. Os níveis de salinidade testados foram 0 e $100 \mathrm{mmol} \mathrm{de}$

\footnotetext{
* Autor para correspondência
} 
cloreto de sódio por litro de solução nutritiva, sendo empregada, como meio hidropônico, a solução de Hoagland e Arnon (1950).

As sementes, fornecidas pela Empresa Pernambucana de Pesquisa Agropecuária (IPA), foram postas para germinar em areia lavada. Aos oito dias após a semeadura, as plântulas foram pesadas e em seguida transplantadas para vasos de polietileno com capacidade para 2,5 litros, onde foram cultivadas em meio hidropônico com e sem adição de cloreto de sódio de acordo com os tratamentos. Para efeito da aeração do sistema radicular, utilizou-se pequenos compressores de ar. Os níveis das soluções nutritivas foram completados diariamente com as próprias soluções, sendo as mesmas substituídas a cada 10 dias.

Trinta dias após o transplante para o meio hidropônico, as plantas foram coletadas. Foram mensuradas as massas das matérias frescas e secas das folhas, caules e raízes, e a área foliar. Para a avaliação da área foliar foi utilizado o medidor portátil de área LICOR, modelo LI3000A. Com base nestes parâmetros e seguindo recomendações de Benincasa (1998), calculouse a alocação da biomassa das folhas, caules e raízes, a taxa de crescimento absoluto em termos de matéria fresca, área foliar e a razão de área foliar.

Os resultados obtidos foram submetidos à análise estatística, mediante análise de variância e estatística descritiva (Gomes, 1977).

\section{RESULTADOS E DISCUSSÃO}

$\mathrm{O}$ tratamento salino não afetou significativamente a alocação da biomassa nas folhas das duas espécies estudadas (Figura 1A e Tabela 1). No entanto, independente dos tratamentos, este parâmetro foi ligeiramente superior nas plantas de milho, quando comparadas com as plantas de tomate. Cerca de 32 a $35 \%$ da matéria fresca total das plantas foram alocadas para o tecido foliar, sendo o restante distribuído entre caules e raízes. Em plantas de arroz, Campos et al. (1989) observaram reduções bastante significativas no peso da lâmina foliar e na matéria seca total, devido ao efeito do cloreto de sódio. Verificaram ainda que o crescimento das plantas foi afetado pelo fechamento precoce dos estômatos.

A maior fração da matéria fresca das plantas foi alocada para o caule, de modo que seus valores oscilaram entre 36 e $44 \%$ (Figura 1B). Independente dos tratamentos aplicados, as plantas de tomate alocaram mais matéria fresca no caule do que as plantas de milho. Ambas as espécies sofreram uma redução na fração da biomassa do caule, devido ao estresse salino.

A biomassa alocada para as raízes das duas espécies não diferiu significativamente, sendo que seus valores oscilaram entre 25 e $30 \%$ da matéria fresca total das plantas (Figura 1C). O estresse salino provocou aumento na alocação da biomassa das raízes de ambas as espécies estudadas. Este tipo de resposta poderá estar associado a um mecanismo de tolerância das plantas ao estresse salino, haja vista que em condições de estresse as plantas passam a investir mais na biomassa do sistema radicular, objetivando aumentar a capacidade de absorção de nutrientes. Este comportamento contudo, não foi verificado por O'leary (1975), em plantas de feijão cultivadas durante um período de 25 dias com cinco níveis de salinidade $(0,0 ; 5,6 ; 7,0 ; 8,4$ e 9,8 g. $\mathrm{L}^{-1}$ de $\mathrm{NaCl}$ ). O referido autor relata uma redução no peso da matéria fresca das raízes em função do aumento da salinidade, com produções de 39,$1 ; 19,2 ; 15,6 ; 16,2$ e 13,6 g, respectivamente. Por outro lado, trabalhando com três cultivares de algodão (Gossypium hersutum) em solução nutritiva com e sem adição de $\mathrm{NaCl}$, Rebouças et al. (1989) verificaram que a matéria seca da raiz das cultivares BR-1 e Detalpine Smooth Leaf aumentou durante os primeiros 14 dias de cultivo em meio salino, numa proporção de 29,5 e $21,9 \%$, respectivamente, em relação ao tratamento controle. Johnson (1991), submetendo dois genótipos de trigo encrespado a dois tratamentos salinos, correspondentes aos potenciais osmóticos de 0,0 e - $0,6 \mathrm{MPa}$, por um período de cinco semanas, não observou diferenças significativas entre o peso da matéria seca da raiz de plantas controle e estressadas. 

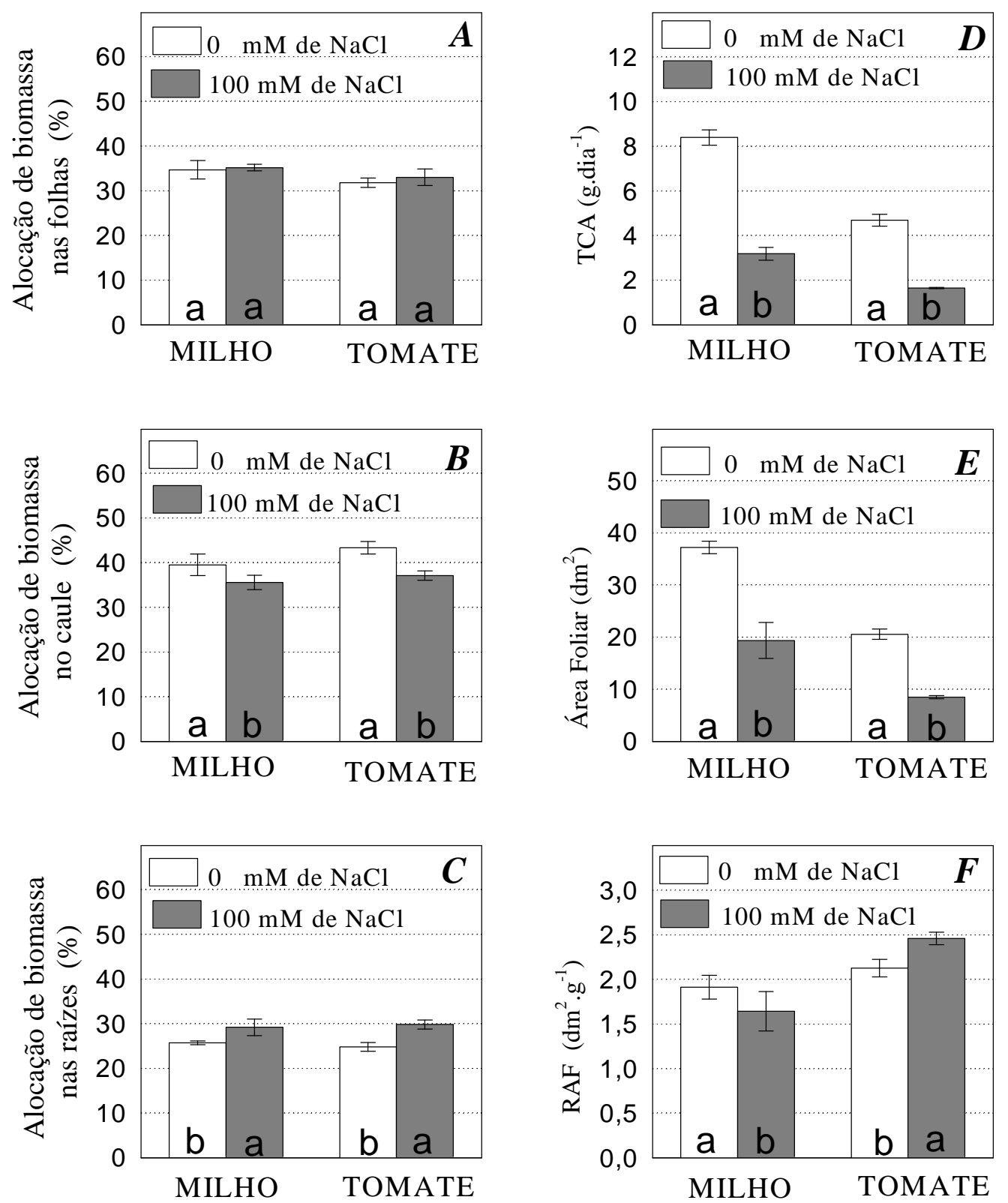

Figura 1. Alocação de biomassa das folhas (A), caules (B) e raízes (C), taxa de crescimento absoluto (D), área foliar (E) e razão de área foliar (F), em plantas de milho e tomate cultivadas em solução nutritiva por um período de 30 dias, com e sem adição de $\mathrm{NaCl}$. Dentro das barras, as letras iguais não diferem significativamente entre si pelo teste de Tukey so nível de $5 \%$ de probabilidade. 
Tabela 1. Síntese da análise estatística das variáveis de crescimento, referentes a uma espécie $\mathrm{C}_{3}$ e uma espécie $\mathrm{C}_{4}$ cultivadas em casa de vegetação sob estresse salino.

\begin{tabular}{lcccc}
\hline \multirow{2}{*}{\multicolumn{1}{c}{ PARÂMETRO }} & \multicolumn{2}{c}{ MILHO } & \multicolumn{2}{c}{ TOMATE } \\
\cline { 2 - 5 } & Valor de P* & CV $(\%)$ & Valor de P* & CV $(\%)$ \\
\hline Alocação de Biomassa nas Folhas & 0,676 & 4,43 & 0,308 & 4,70 \\
Alocação de Biomassa no Caule & 0,032 & 5,40 & 0,001 & 3,09 \\
Alocação de Biomassa nas Raízes & 0,010 & 4,84 & 0,001 & 3,66 \\
Taxa de Crescimento Absoluto & 0,000 & 5,45 & 0,000 & 5,96 \\
Área Foliar & 0,000 & 9,12 & 0,000 & 5,14 \\
Razão de Área Foliar & 0,083 & 10,29 & 0,002 & 3,74 \\
\hline * Valor de P representa o grau de significância com base na análise de variância (teste F) &
\end{tabular}

A taxa de crescimento absoluto (TCA) de ambas as espécies decresceu consideravelmente devido ao tratamento salino, sendo esta queda maior nas plantas de tomate do que nas de milho (Figura 1D). As plantas de tomate cultivadas sem adição de cloreto de sódio cresceram a uma taxa de $4,69 \mathrm{~g}$ por dia enquanto que as tratadas com cloreto de sódio cresceram apenas 1,65 g por dia. Para o milho a TCA foi de 8,40 g por dia nas plantas testemunhas e 3,19 nas estressadas. Em termos percentuais, ocorreu uma queda correspondente a $64,71 \%$ para o tomate e 62,07 $\%$ para o milho, em virtude do tratamento salino. A taxa de crescimento absoluto dá uma idéia da velocidade média do crescimento ao longo do período de observação (Perez, 1995). O milho mostrou ter uma maior velocidade média de crescimento do que o tomate, tanto nas condições normais como na presença do $\mathrm{NaCl}$.

Tanto o milho como o tomate apresentaram redução na área foliar, como consequência do estresse salino (Figura 1E). O milho apresentou 37,22 e 19,35 $\mathrm{dm}^{2}$ de área foliar, respectivamente quando cultivadas sem, e com adição de cloreto de sódio. A área foliar do tomate cultivado como testemunha foi de 20,58 $\mathrm{dm}^{2}$, enquanto que as plantas tratadas com cloreto de sódio tiveram $8,49 \mathrm{dm} 2$ de área foliar. Em termos percentuais, o tratamento salino causou uma redução de 48,01 \% na área foliar do milho e $58,75 \%$ na área foliar do tomate. Estudando o efeito de quatro níveis de salinidade do solo (Cees= 0,$90 ; 3,72 ; 6,60$ e $10,75 \mathrm{dS} / \mathrm{m})$ nos cinco primeiros meses de cultivares de bananeira, Araújo Filho et al. (1995) observaram que os dois últimos níveis afetaram sensivelmente a cultura, sendo esse efeito mais pronunciado na área foliar, com variação entre cultivares. Segundo os mesmos autores, a área foliar total das plantas cultivadas no tratamento mais severo foi $55 \%$ menor do que a verificada na testemunha. A redução na área foliar pode estar associada à diminuição da extensibilidade da parede celular, que por sua vez depende especialmente do balanço hídrico das células do tecido foliar. Quando a planta é submetida a estresse salino, o balanço hídrico é alterado, provocando diminuição no potencial de pressão, o qual é necessário para induzir a distensão da parede celular e consequentemente o crescimento da folha (Prisco, 1980).

A razão de área foliar (RFA) é um parâmetro fisiológico que expressa a área foliar útil para a fotossíntese (Benincasa, 1998). No presente trabalho este parâmetro foi o único analisado que diminuiu no milho e aumentou no tomate, como consequência do tratamento salino (Figura 1F). O milho apresentou uma redução de 14,07 $\%$ e o tomate um aumento de $15,60 \%$ na razão de área foliar. Tais resultados não coincidem com os obtidos por Allarcon et al. (1994) para dois genótipos de tomate cultivados em condições de estresse salino em câmara de crescimento, nos quais foram verificados decréscimos na razão de área foliar. O contraste entre os resultados obtidos no presente trabalho e os observados pelos autores citados, pode estar relacionado com as condições de cultivo, e com as diferenças genotípicas. O decréscimo da RFA em plantas de milho submetidas à salinidade poderá estar associado a um mecanismo de tolerância ao estresse salino, uma vez que nestas condições as plantas passam a necessitar de uma menor área foliar para a produção de matéria seca, apresentando dessa forma uma maior eficiência fotossintética. 


\section{CONCLUSÕES}

Com base nas condições experimentais e nos parâmetros analisados pode-se concluir que:

- A adição de $100 \mathrm{mM}$ de cloreto de sódio à solução nutritiva não afeta a alocação de biomassa de folhas nem de tomate nem de milho;

- tratamento salino provoca aumento na alocação de biomassa das raízes e diminui a do caule em ambas as espécies estudadas;

- A taxa de crescimento absoluto do tomate foi mais severamente afetada pela salinidade do que a do milho;

- A área foliar de ambas as espécies diminuiu com o tratamento salino;

- A razão de área foliar do tomate aumentou em função do tratamento salino, enquanto a do milho diminuiu.

\section{RESUMO}

Plantas de tomate (Lycopersicum esculentum Mill) e de milho (Zea maiz L.) foram cultivadas em meio hidropônico, em presença de 0 ou 100 mmol de $\mathrm{NaCl}$ por litro de solução nutritiva. Trinta dias após o início da aplicação dos tratamentos foi realizada coleta para a análise dos parâmetros de crescimento. A taxa de crescimento absoluto de ambas as espécies diminuiu com a salinidade. O tratamento salino não afetou a alocação de biomassa das folhas, provocou uma diminuição na alocação da biomassa do caule e aumento da alocação da biomassa das raízes das plantas de tomate e de milho. Ocorreu uma redução de $48,01 \%$ na área foliar das plantas de milho e de 58,75\% nas de tomate, devido ao tratamento salino. A razão de área foliar nas plantas de milho foi reduzida em $14,07 \%$ enquanto nas de tomate tratadas com cloreto de sódio aumentou $15,49 \%$. Os resultados obtidos sugerem que as plantas de milho são mais tolerantes à salinidade que as de tomate.

\section{REFERÊNCIAS}

Allarcon, J. J.; Sanchez-Blanco, M. J.; Bolarin, M. C.; Torrecilas, A. (1994), Growth and osmotic adjustment of two tomato cultivars during and after salt stress. Plant and Soil, 166, 75-82
Araújo Filho, J. B.; Gheyi, H. R.; Azevedo, N. C. (1995), Tolerância da bananeira à salinidade em fase inicial de desenvolvimento. Pesq. Agrop. Bras., 30, 989-997

Benincasa, M. M. P. (1998), Análise de crescimento de plantas. FCAV-UNESP, Jaboticabal

Campos, I. S.; Ferreira, L. G. R.; Assunção, M. V. (1989), Efeitos salinos no crescimento e desenvolvimento do arroz: alterações fisiológicas. Pesq. Agrop. Bras., 24, 11111118

Epstein, E. (1975), Nutrição mineral das plantas: princípios e perspectivas. Universidade de São Paulo, Rio de Janeiro

Fletcher, R.A. (1969), Retardation of leaf senescence by benzyl adenine in intact bean plants. Planta, 89, 1-8

Gomes, F.P. (1977), Curso de estatística experimental. Nobel, Piracicaba

Hoagland, D. R.; Arnon, D.I. (1950), The waterculture method for growing plants without soil. Circular n. 347, Agricultural Experiment Station, California

Johnson, R. C. (1991), Salinity resistance, water relations, and salt content of crested and tall wheatgrass accessions. Crop Science, 31, 730-734

Marschner, H. (1990), Mineral nutrition of higher plants. Academic Press, London

O'leary, J. W. (1975), Hight humidity overcomes lethal levels of salinity in hydroponically grown salt-sensitive plants. Plant and Soil, 42, 717-721

Perez, S. C. J. G. A. (1995), Crescimento e resistência à seca da algarobeira (Prosopis juliflora SW. DC.) cultivada em solo de cerrado, com ou sem adubo orgânico. Pesq. Agrop. Bras., 30, 595-604

Prisco, J. T. (1980), Alguns aspectos da fisiologia do "stress" salino. Revista Brasileira de Botânica, 3, 85-94

Rebouças, M.A.A.; Façanha, J.G.V.; Ferreira, L.G.R.; Prisco, J.T. (1989), Crescimento e conteúdo de $\mathrm{N}, \mathrm{P}, \mathrm{K}$ e $\mathrm{Na}$ em três cultivares de algodão sob condições de estresse salino. Rev. Bras. Fisiol. Vegetal, 1, 79-85

Reveived: July 17, 1997; Revised: September 29, 1997; Accepted: September 22, 1999. 